\title{
Soft Targets: Definition and Identification ${ }^{1}$
}

\author{
Tomáš ZEMAN²
}

\begin{abstract}
Available definitions describe a soft target as a location with high vulnerability, but a low level of protection. However, such general definitions can hardly be used in the process of soft targets identification. The aim of the article is to create a temporary specific definition that could be utilised for this purpose. The suggested definition of a soft target is based on performed statistical analysis of 275 cases of terrorist attacks aimed against soft targets in the European Union from 2000 to 2015. In the definition, a soft target is characterised based on the probability of a terrorist attack occurrence and the expected number of casualties caused by the attack.
\end{abstract}

Keywords: soft targets, terrorist attacks, crisis management, definition.

\section{Introduction}

Recently, great attention has been paid to the issue of soft targets and measures for the increase of their security. In the United States (US) and Europe, there is an increasing number of violent attacks on soft targets in order to injure as many people as possible. Due to their attractiveness, ease of access and accessibility, terrorist groups increasingly seek them. Libicki, Chalk and Sission [1] presumed that this trend is caused by the hardening of prominent targets such as the Pentagon or White House after September 11, 2001. The difficulty of attacking these prominent targets leads terrorist groups to focus their attacks against soft targets, which are far more vulnerable.

Unfortunately, there is no universally recognised definition of soft targets to date. According to Fagel and Hesterman, [2] a soft target is generally "any person or thing that is vulnerable to attack but not protected". Recently, in its Fourth progress report towards an effective and genuine Security Union, the European Commission [3] defined soft targets as locations that "are vulnerable and difficult to protect and are also characterised by the high likelihood of mass casualties in the event of an attack". Nevertheless, both definitions are very common, which does not allow their use in the process of soft targets identification. The creation of more specific definition of soft targets would significantly facilitate the process of soft targets identification and contribute to a better understanding of terrorist aims and targets selection.

\footnotetext{
1 The work was created as a commission of the National University of Public Service under the priority project KÖFOP-2.1.2-VEKOP-15-2016-00001 titled “Public Service Development Establishing Good Governance”.

2 Ph.D., assistant Professor, Department of Military Science Theory, Faculty of Military Leadership, University of Defence, Brno, Czech Republic; e-mail: tomas.zeman2@unob.cz; ORCID ID: 0000-0001-7269-4994
} 
In terms of soft targets, the greatest attention nowadays is paid to objects or events that involve a large number of people in relatively small areas such as temples, schools, universities, hospitals, sport events, concerts, restaurants, hotels, bus/train stations etc. Although all these facilities or events are similar in many aspects, "not all such targets are equally vulnerable”, as noted by Asal et al. [4] In addition, it can be assumed that individual soft targets differ also in their popularity among terrorists. Unfortunately, practically no quantitative research of soft target vulnerability and their preferences by terrorists has been performed apart from the notable exception of the above mentioned study by Asal et al. [4]. The aim of this article is to contribute to the formulation of a soft target specific definition based on the identification of soft targets with the highest vulnerability and/or the highest probability of a terrorist attack. In order to achieve this goal, a statistical analysis of data about terrorist attacks committed in the European Union (EU) between 2000 and 2015 was performed.

\section{Methods}

The Global Terrorism Database [5] was utilised as a data source. All terrorist acts committed in the EU between 2000 and 2015 were selected from the Global Terrorism Database (GTD). Furthermore, only terrorist acts targeted against targets listed in the Table 1 were selected using the variable "targsubtype1" according to the GTD Codebook. [6] The result of this selection was 275 cases of terrorist attacks against soft targets from 19 target categories according to the GTD. [5] On the other hand, there were no documented terrorist attacks against targets from the Civilian maritime and Port categories according to the GTD in the given period. For this reason, these two categories were excluded from further statistical analyses. The number of casualties were calculated as the sum of persons killed or wounded during the attacks based on the variables "nkill” and "nwound" from the GTD.

For each terrorist attack, additional information (i.e. occurrence of the attacker's attempt to penetrate the structure, success of this penetration and evidence of some terrorist group engagement during preparation of the attack) were traced in publicly available sources, particularly from websites of news media such as BBC News, The New York Times etc.

Penetration of a structure is any technique of entering a structure with the intention of committing a terrorist act, e.g. armed assault with a rifle, as well as walking into a structure with a hidden bomb. On the other hand, cases when a terrorist attack was committed outside the building, such as the explosion of a bomb placed in a garbage bin near its entrance or the throwing of a Molotov cocktail into the building from the street were not considered as a penetration attempt.

A terrorist attack is considered to have been organised by a terrorist group in two cases: a) A terrorist attack is claimed by the group and this claim is not questioned by any relevant source, e.g. conclusions from a police investigation; $b$ ) Involvement of a terrorist group is proved during a police investigation. In cases when two or more terrorist groups claim one terrorist attack, but it is not clear which claim is true, the terrorist attack is considered to have been organised by a terrorist group. Any other terrorist act not corresponding to any of the aforementioned criteria is not considered to have been organised by a terrorist group. This procedure leads to the division of all terrorist attacks into two 
groups: a) terrorist attacks demonstrably organised by a terrorist group; $b$ ) terrorist attacks committed by an individual, i.e. lone wolves or lone actors, and terrorist attacks organised by a terrorist group, but with a lack of evidence of the terrorist group's engagement.

Table 1. Coding of selected soft targets according to the GTD Codebook [6], with the number of incidents and the mean number of casualties between 2000 and 2015.

(Based on data from GTD [5].)

\begin{tabular}{rlccl}
\hline Coding & \multicolumn{1}{c}{ Target } & $\begin{array}{c}\text { Number of } \\
\text { incidents }\end{array}$ & $\begin{array}{c}\text { Mean } \\
\text { number of } \\
\text { wounded }\end{array}$ & $\begin{array}{c}\text { Mean } \\
\text { number of } \\
\text { dead }\end{array}$ \\
\hline 2 & Restaurant/bar/café & 29 & 3.759 & 1.345 \\
8 & Hotel/resort & 19 & 3.353 & 0.278 \\
11 & Entertainment/cultural/stadium/casino & 36 & 9.629 & 2.6 \\
44 & Airport & 8 & 0.375 & 0 \\
49 & School/university/educational building & 15 & 2.333 & 0.733 \\
57 & Civilian maritime & 0 & 0 & 0 \\
60 & Port & 0 & 0 & 0 \\
74 & Marketplace/plaza/square & 7 & 5 & 0.143 \\
78 & Procession/gathering & 4 & 5.75 & 0.25 \\
79 & Public areas & 23 & 0.957 & 0.087 \\
81 & Museum/cultural centre/cultural house & 6 & 0 & 0.667 \\
86 & Place of worship & 63 & 0.27 & 0.016 \\
96 & Tour bus/van/vehicle & 1 & 30 & 6 \\
99 & Bus (excluding tour bus) & 9 & 0.111 & 0 \\
100 & Train/train tracks/trolley & 44 & 40.977 & 4.341 \\
101 & Bus station/stop & 2 & 0 & 0 \\
102 & Subway & 3 & 0 & 0 \\
103 & Bridge/car tunnel & 1 & 0 & 0 \\
104 & Highway/road/toll/traffic signal & 5 & 0 & 0 \\
& Total & 275 & 8.989 & 1.28 \\
\hline
\end{tabular}

Note: Mean numbers were calculated as the sum of wounded or dead people divided by the number of incidents.

Based on research samples consisting of data from GTD [5] and the aforementioned additional variables, a statistical analysis was performed for soft targets categories with at least 15 cases. All calculations were performed in statistical software R [7]. The relationship between variables was assessed using Spearman's rank correlation coefficient (R).

\section{Results and Discussion}

Regarding the type of used weapon, bomb attacks are by far the most frequent (Table 2). Terrorist attacks carried out with explosives or an incendiary constitute $90.2 \%$ of all attacks against soft targets in the EU between 2000 and 2015. Based on the results of performed analysis, train/train tracks/trolley, entertainment/cultural/stadium/casino, restaurant/bar/ 
café and hotel/resort are the soft targets with the highest number of victims caused by terrorist attacks (see Figure 1, Table 1).

Table 2. Relative frequencies of weapon type in the sample. (Based on data from GTD [5].)

\begin{tabular}{lr}
\hline Weapon type & $\mathbf{\%}$ \\
\hline Explosives/bombs/dynamite & 64.4 \\
Incendiary & 25.8 \\
Firearms & 4.7 \\
Melee & 2.9 \\
Others & 2.2 \\
\hline
\end{tabular}

Note. Frequencies based on variable "weaptype1” from GTD [6].

As can be seen in Figure 1, the highest number of victims was caused by terrorist attacks against soft targets from the GTD category train/train tracks/trolley. Almost all documented victims were killed or wounded as the result of the terrorist attacks in Madrid on 11 March 2004, where a series of ten bomb explosions occurred on trains on Madrid's commuter line during the morning rush hour. As seen in Table 1 and in Figure 1, the number of attacks against targets from this category is also very high. There were 44 attacks documented by the GTD [5] between 2000 and 2015. The absolute majority of them was bombing (70\%) or arson (27\%) attacks as seen in Table 2. Nevertheless, most of these attacks were either unsuccessful or with no intention to kill. This directly correlates with the fact that most of the bomb attacks were performed at night or in the early morning hours. Bomb attacks against rail lines (36\%) or train stations (36\%) are the most frequent modus operandi, whereas direct assaults against trains are relatively rare (18\%).

Terrorist attacks against soft targets from the entertainment/cultural/stadium/casino category are very frequent $(\mathrm{n}=36)$, although not highly devastating. These attacks are most frequently bomb attacks against nightclubs, discotheques or bars (44\%), however, stadiums are also a relatively frequent target (14\%). The remaining cases represent attacks against various targets such as concert halls, museums, galleries, sport facilities etc. Attacks against targets from this category are usually not highly lethal. In fact, in most cases, there is evidently no intention to kill: Bomb devices are usually detonated at night outside opening hours and are often preceded by a telephone call of the upcoming bomb attack. In some cases, these attacks are more like vandalism. The reason why these soft targets have the second highest mean number of casualties caused by terrorist attacks can be found in the Paris attacks on 13 November 2015, specifically the Bataclan concert hall massacre. The Bataclan attack has shown the vulnerability of this kind of soft target. In this case, three perpetrators armed with firearms were able to penetrate the building with six security agents on duty that night being unable to stop them. The massacre lead to 90 people killed and 217 wounded according to GTD. [5] On the other hand, security measures proved to be effective at another terrorist attack performed by ISIL that day in Paris, the suicide bombing at Stade de France, when three suicide bombers attempted to get inside the stadium where 79,000 people were watching a friendly football game between France and Germany. This plan failed after a security guard discovered the suicide vest of the first bomber and prevented him from entering the stadium. As a result, instead of hundreds of dead, only one 
person was killed, when all three perpetrators detonated themselves near the entrance gates to the stadium.

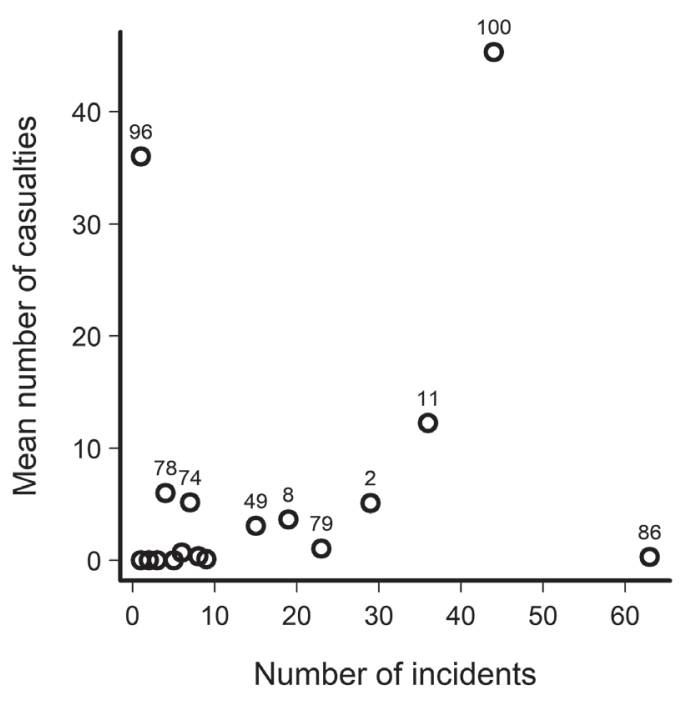

(Each type of soft target marked uses the coding of variable "targsubtype1" from GTD, for details see Table 1.)

Figure 1. Number of terrorist attacks against soft targets and the mean number of casualties (persons killed or wounded during the attacks) in the European Union between 2000 and 2015. (Based on data from GTD [5].)

Another very common target is a restaurant/bar/café. In these places, it is very unlikely that there are security guards, cameras, etc. that could prevent a terrorist attack. According to the GTD, [5] there were 29 terrorist attacks against these types of soft targets. However, the actual reasons why these targets have the third highest number of victims are due to the Paris attacks on 13 November 2015, specifically on restaurants in the area of the $10^{\text {th }}$ arrondissement. The remaining terrorist attacks against the targets from this category were far from being so devastating. The modus operandi of these attacks was quite similar to the attacks against targets from the entertainment/cultural/stadium/casino category: In most cases, some kind of explosive device was used (76\%). The bomb attacks were often performed outside opening hours indicating that the primary goal of these attacks was not to kill civilians. In six cases, the attack was announced in advance, usually by an anonymous telephone call. 


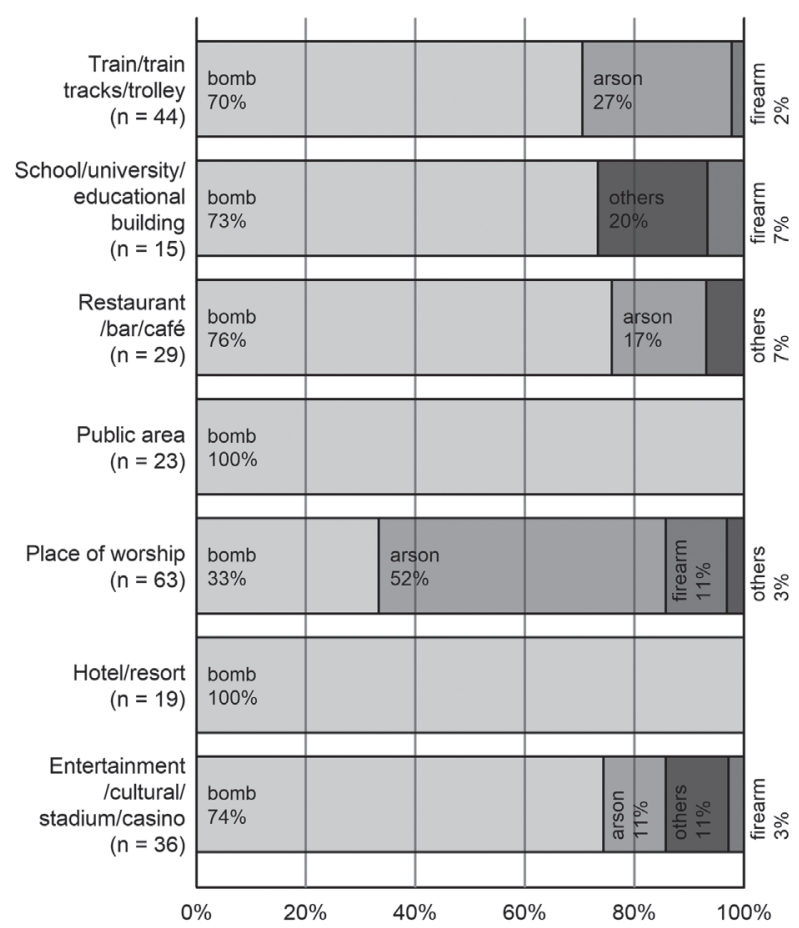

Figure 2. Frequencies of different techniques of terrorist attacks against seven types of soft targets most frequently exposed to terrorist attacks. (Based on data from GTD [5].)

Other relatively frequent targets of terrorist attacks were soft targets from the GTD category hotels/resorts $(n=19)$. [5] Interestingly enough, the most frequent targets were Spanish or French hotels or resorts. This corresponds with the fact that in most cases the attacks were carried out by Basque or Corsican separatist groups, e.g. ETA (Euskadi ta Askatasuna). Spanish hotels/resorts were targeted in 53\% and French hotels/resorts in $37 \%$ of the cases. Detonated explosives were used as the primary technique of attack in all cases. It is quite easy to get explosives inside the hotels/resorts because the main entrance is usually unguarded and there is no luggage check of the guests.

Regarding the tour bus/van category, there was only one documented terrorist attack between 2000 and 2015, however, with many fatalities. It was a suicide bomber attack on an Israeli tourist bus in Burgas, Bulgaria, claimed by Hezbollah. This attack resulted in 6 dead and 30 injured passengers.

There were several documented terrorist attacks against soft targets from the GTD category school/university/educational buildings with moderate lethality. For the most part, they were bomb attacks (73\%). [5] However, there is also a relatively high percentage of direct assaults carried out by assailants armed with firearms or knives (20\%). So far, probably the worst attack against school/university/educational buildings was performed by a teenage 
Finnish student on 7 November 2007 at the Jokela High School, when a student carried out a school shooting and killed seven students, a teacher, and himself with a handgun.

There were only seven documented terrorist attacks against targets from the marketplace/ plaza/square category; however, one of them led to a great number of casualties. It was a bombing attack that took place in a supermarket in the central part of Riga on 17 August 2000 and resulted in 1 dead and 34 injured. The other six attacks were only slightly lethal, together leading only to one wounded person.

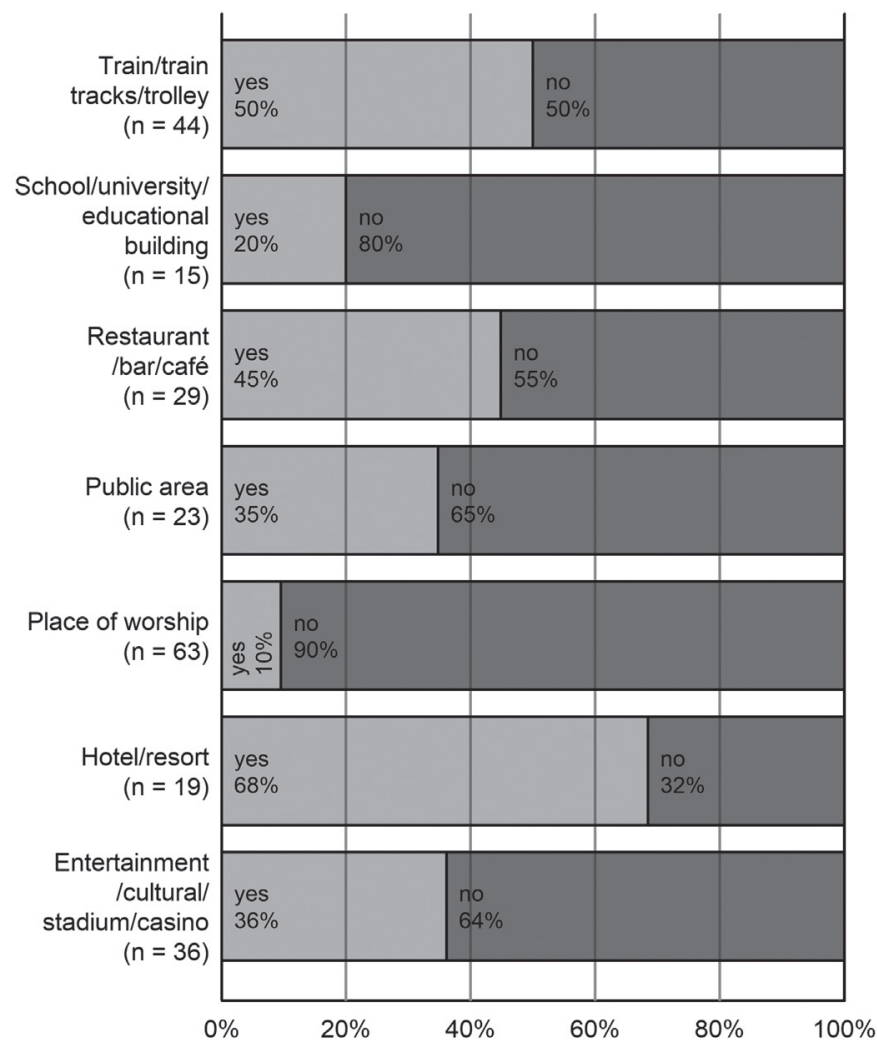

Figure 3. Frequencies of terrorist attacks apparently organised by terrorist groups in seven types of soft targets most frequently exposed to terrorist attacks. [Edited by the author.]

One common soft target that terrorist organisations choose as their target are public areas (gardens, parking lots, garages, beaches, public buildings and camps). These places are very attractive to terrorists because they are public, often completely unguarded and as a rule, there is a large number of people on site. However, despite the large number of terrorist attacks in public areas $(n=23)$, their lethality is relatively low $(0.087$ dead and 0.957 wounded people per attack). Similarly, terrorist attacks against places of worship as a soft target are frequent in all over Europe $(n=63)$, they are in fact the most frequently attacked soft targets. In spite of this, their lethality is very low ( 0.016 dead and 0.27 wounded people per attack). Regarding these soft targets, an interesting geographical distribution can 
be observed: attacks against places of worship in France and Germany give 52\% of all the terrorist attacks against these types of soft targets. The most targeted places are synagogues (30\%) and mosques (43\%) in all of Europe. In most cases, no terrorist organisation claimed responsibility for these attacks and there was no convincing evidence indicating that the attack was committed by any terrorist organisation (90\%) as seen in Figure 3. The most widespread techniques of attack were explosives and arson attacks (setting fires or throwing Molotov cocktails). In contrast, terrorist attacks against processions/gatherings are very rare; in fact, only four such terrorist attacks were documented in the selected period; however, for this category the third highest mean number of casualties among all soft targets categories has been reported ( 0.25 dead and 5.75 wounded people per attack).

The frequency of terrorist attacks against all other types of soft targets categories or the number of casualties caused by these attacks proved to be very low.

The positive correlation between terrorist group involvement and the number of casualties, as seen in Figure 4, indicates that terrorist attacks organised by terrorist groups are deadlier than terrorist attacks committed by individuals. This is apparently caused by a higher rate of bomb attacks in terrorist attacks committed by terrorist organisations (83\% of all terrorist attacks organised by terrorist organisations) compared to terrorist attacks committed by individuals or by an unknown perpetrator ( $58 \%$ of all terrorist attacks performed by individuals or an unknown perpetrator).

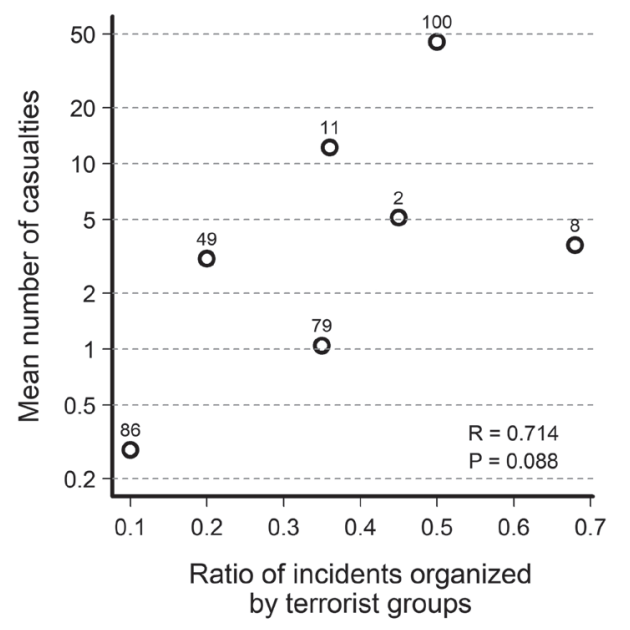

("R" represents Spearman's rank correlation coefficient and "P" the respective p values. Each type of soft target marked uses the coding of variable "targsubtype1" from GTD, for details see Table 1.)

Figure 4. Relationship between ratios of terrorist attacks prepared by terrorist groups and the mean number of casualties. (Based on data from GTD [5]).

There are also significant differences in the rate of penetration attempts into structures in selected soft target categories (Figure 5). There is a very high penetration attempt rate 
in targets from the train/train tracks/trolley, school/university/educational building and the restaurant/bar/café categories. This rate is slightly less than that of the category of public areas, which includes public gardens, parking lots, beaches, camps etc., [6] relatively low in targets from the categories of place of worship and hotel/resort and very low in the category of entertainment/cultural/stadium/casino. This trend apparently corresponds with the extent of security measures which are usually adopted for soft targets from each category. For example, there are no security measures in fact that could prevent anyone from tossing a bomb, incendiary or firearm into a train, trolley, school or restaurant. Unlike these objects, many soft targets from the category of entertainment/cultural/stadium/casino and some targets from the categories of hotel/resort and place of worship usually perform personal entrance checks. This demonstrates the importance of such security measures in the prevention of terrorist attacks. The best example of this is the foiling of the suicide bomber during a personal check at the entrance into Stade de France during the 13 November terrorist attacks in Paris, which consequently saved tens or maybe hundreds of lives.

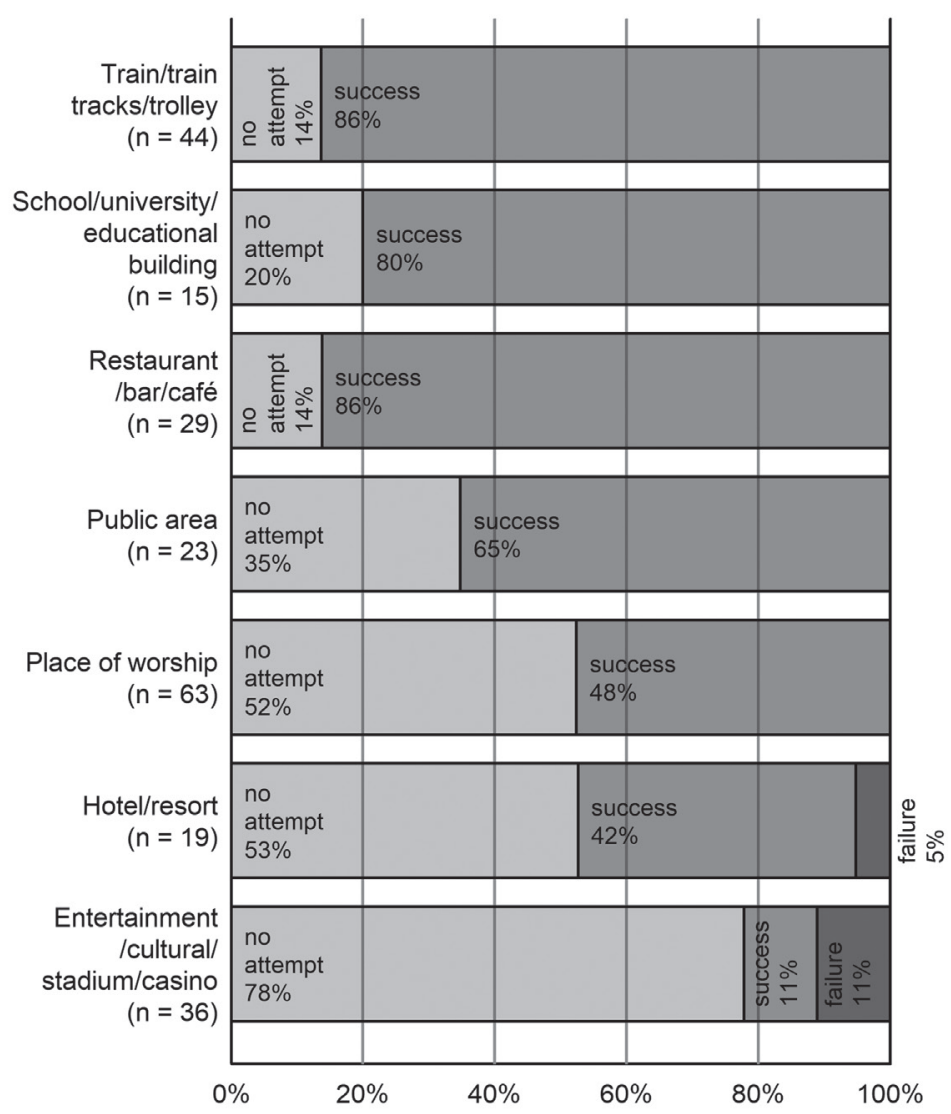

Figure 5: Frequencies of attempts to penetrate a structure and success of the penetration in seven types of soft targets most frequently exposed to terrorist attacks. 


\section{Conclusions}

Based on the results of the statistical analysis, it was found that different types of soft targets vary greatly concerning the risk of terrorist attack. One of two basic features of soft targets according to the common definitions is vulnerability. In this study, vulnerability was measured by lethality, i.e. the mean number of casualties caused by terrorist attacks against each soft target category. Vulnerability is given by the concentration of people, efficiency of security measures and quality of terrorist attack performance. There were four soft target categories with no casualties at all and four others with the mean number of casualties lower than one person per attack. A good example of this type of soft target is places of worship. During the selected period of sixteen years, the GTD [5] contained 63 terrorist attacks against soft targets from this category in the EU. However, all these attacks ended with the death of only 1 person and 17 people wounded. Besides the low level of professionalism of these terrorist attacks, it is also due to the fact that the density of people at places of worship is usually relatively low. Despite this, places of worship are a very popular target due to their symbolic meaning. However, it is questionable if the structure from this group should be classified as a soft target.

On the other hand, there are target categories that are rarely hit by terrorist attacks, even though these attacks are extremely deadly. A good example is targets from the GTD category of tour bus/van/vehicle. There was only one terrorist attack against these targets in the selected period in the EU, i.e. the suicide bomber attack on an Israeli tour bus in Burgas, however, with great impact (six people killed, 30 wounded). [5]

For these reasons, both the frequency and lethality of terrorist attacks against soft targets were considered as valuable variables for soft target identification. Together, they reflect all the important aspects of terrorist attacks against soft targets, i.e. the concentration of people on site, the efficiency of security measures and the target preferences of terrorists. Based on the results of this study, the provisional two-criterion definition of a soft target is suggested: "A soft target is a location where the probability of a terrorist attack incidence per year exceeds $0.001 \%$ and the expected number of casualties caused by the attack exceeds 1 dead or wounded person.”

This specific definition can be used for the preliminary classification of an object as a soft target. The expected number of casualties can be estimated based on GTD [5] as the mean number of casualties for the selected GTD category of soft targets, e.g. the hotel/resort category in a region, e.g. the EU. The probability of terrorist attacks for the selected soft target in the region can be approximated as the number of terrorist attacks in the region in the selected period divided by the period length in years and the total number of soft targets of this type in the region, e.g. the total number of hotels and resorts in the EU.

It can be seen that by this procedure the probability of a terrorist attack for one object from a given soft target category can be calculated. This probability was deliberately preferred over the probability of a terrorist attack against the entire category of soft targets. This approach was used because the probability for an individual object reflects not only the target preferences of terrorists, but also the possibilities of the target's protection. For example, even though the frequencies of terrorist attacks against targets from the categories of marketplace/plaza/square and airport are similar, the possibilities for their protection are utterly different due to their numbers. At the same time, several hundreds of civil airports 
operate in the EU; there are at least tens of thousands of markets in the same territory, which makes their protection practically impossible.

However, the proposed procedure is based solely on historical data. As such, it cannot be perfect and should only be considered temporary. The modus operandi of terrorist attacks, as well as target preferences of terrorists, changes quickly. For this reason, soft target identification based solely on historical data is necessarily not entirely accurate. Moreover, the method used for determination o f the probability of a terrorist attack against individual soft targets is only approximate. In fact, the probability of a terrorist attack differs not only among soft target GTD categories, but also between two soft targets from one GTD category. For example, the marketplace in the capital or large city has a significantly higher probability of a terrorist attack than a marketplace in a village. More sophisticated methods for the determination of both probability of a terrorist attack and the mean number of casualties should be elaborated in the future. In particular, the method should allow for the assessment of terrorist attack probability for an individual soft target taking into account its position, size and adopted security measures.

\section{References}

[1] LIBICKI, M. C. - CHALK, P. - SISSION, M.: Exploring Terrorist Targeting Preferences. Santa Monica, RAND Corporation, 2007. www.rand.org/content/dam/rand/pubs/ monographs/2007/RAND_MG483.pdf (Downloaded: 22.11.2017)

[2] FAGEL, M. J. - HESTERMAN, J.: Soft Targets and Crisis Management: What Emergency Planners and Security Professionals Need to Know? New York, Routledge, 2016. DOI: https://doi.org/10.4324/9781315451091

[3] COM/2017/041 final. Fourth progress report towards an effective and genuine Security Union. Luxembourg, Publications Office of the EU, 2017.

[4] ASAL, V. H. - RETHEMEYER, R. K. - ANDERSON, I. - STEIN, A. - RIZZO, J. - ROZEA, M.: The Softest of Targets: A Study on Terrorist Target Selection. Journal of Applied Security Research, 43 (2009), 258-278. DOI: https://doi. org/10.1080/19361610902929990

[5] Global Terrorism Database (GTD). National Consortium for the Study of Terrorism and Responses to Terrorism, 2017. www.start.umd.edu/research-projects/global-terrorismdatabase-gtd (Downloaded: 22.11.2017)

[6] Global Terrorism Database - Codebook: Inclusion Criteria and Variables. June 2017. National Consortium for the Study of Terrorism and Responses to Terrorism. Maryland, University of Maryland, 2017. www.start.umd.edu/gtd/downloads/Codebook.pdf (Downloaded: 22.11.2017)

[7] R Development Core Team: R: A language and environment for statistical computing. Vienna, R Foundation for Statistical Computing, 2017. 